\title{
Gambling with Stimulus Payments: Feeding Gaming Machines with Federal Dollars.
}

\author{
Jenny Lye and Joe Hirschberg \\ February, 2013
}

Department of Economics, University of Melbourne, Victoria 3010, Australia.

\begin{abstract}
In late 2008 and early 2009 the Australian Federal Government introduced a series of economic stimulus packages designed to maintain consumer spending in the early days of the Great Recession. When these packages were initiated the media suggested that the widespread availability of electronic gaming machines (EGMs, eg. slot machines, poker machines, video lottery terminals) in Australia would result in stimulating the EGMs. Using state level monthly data we estimate that the stimulus packages led to an increase of $26 \%$ in EGM revenues. This also resulted in over $\$ 60$ million in additional tax revenue for State Governments. We also estimate a short-run aggregate income demand elasticity for EGMs to be approximately 2 .
\end{abstract}

Keywords: Stimulus payments, Gambling, EGMs, VLTs, Pokies, Slots

\section{Gambling with Stimulus Payments: Feeding Gaming Machines with Federal Dollars.}

\begin{abstract}
In late 2008 and early 2009 the Australian Federal Government introduced a series of economic stimulus packages designed to maintain consumer spending in the early days of the Great Recession. When these packages were initiated the media suggested that the widespread availability of electronic gaming machines (EGMs, eg. slot machines, poker machines, video lottery terminals) in Australia would result in stimulating the EGMs. Using state level monthly data we estimate that the stimulus packages led to an increase of $26 \%$ in EGM revenues. This also resulted in over $\$ 60$ million in additional tax revenue for State
\end{abstract}


Governments. We also estimate a short-run aggregate income demand elasticity for EGMs to be approximately 2 .

Keywords: Stimulus payments, Gambling, EGMs, VLTs, Pokies, Slots 


\section{Introduction}

The Great Recession that started in 2007 is considered by many to be the worst financial crisis since the 1930s Great Depression. In order to forestall a significant downturn in the Australian Economy, the Australian Government followed the lead of a number of other nations by introducing a series of economic stimulus packages. One component of these stimuli was a series of direct cash payments to individuals and households. The objective of these payments was to boost household consumption spending and consequently reduce the anticipated fall in aggregate demand. However, given the widespread availability of electronic gaming machines (EGMs) in Australia, the proposal of this package raised concerns that a significant portion of these payments would be directed to gaming venues. In this paper we examine the evidence for the pass-through of these payments.

Australia has the distinction of possessing more EGMs per capita and distributing them more widely than any other member nation in the Organization for Economic Cooperation and Development (OECD). ${ }^{1}$ In the 2008-09 financial year there were 185,629 registered EGMs operating in clubs and hotels throughout Australia that took in approximately $\$ 10.5$ billion. ${ }^{23}$ This wide availability of EGMs has come at a price, recent evidence suggests that among those who regularly gamble on the pokies, $15 \%$ are problem gamblers and a further 15\% are considered as "moderate risk" (Australian Productivity Commission 2009). Previous research has linked problem gambling with increased accessibility, poverty, low socio-economic status and substance abuse (Marshall and Wynne 2004). There is also evidence to indicate a tendency for EGMs to be located in more socioeconomically disadvantaged areas (Marshall and Baker 2001).

Soon after the initial stimulus payments were paid, the Australian media began to report splurges at EGM venues. Stories with headlines such as "Massive Pokies Binge" were common in media outlets across Australia (Dowling et al. 2009). Opponents to EGMs began a "Presents not Pokies" campaign (see Ife and Collier 2008) to encourage more retail spending. In addition, government officials responded to such criticisms with statements like "The Australian Government took decisive action to strengthen the economy and we've encouraged responsible spending" (Commonwealth Community Services minister; see Dowling et al. 2009). This was coupled with government denials that stimulus payments were spent at the pokies. A government spokeswoman for the state of Victoria responded to these observations by claiming that "Gaming machine net expenditure figures fluctuate from month to month and we can't assume these variations are caused by a single event" (see Dowling et al. 2009).

\footnotetext{
${ }^{1}$ Here we refer to EMGs to describe a variety of electronic slot machines or video lottery terminals (VLTs) that use random number generators to determine outcomes. The term "pokies" is the Australian vernacular for poker machines, the most common electronic gaming machine in use in Australia. These machines are programmed to provide a regulated probability of a payoff.

2 The term hotel in Australia is used to refer to an establishment that may only have a bar and a tavern, usually with limited or no sleeping accommodation and are run as profit making enterprises. Clubs are usually smaller than a casino and are owned by local organizations such as social and sports clubs which are run for the benefit of the members. The majority of EGMS are located in hotels and clubs.

3 All \$ amounts here are quoted in Australian dollars unless otherwise stated. During the period of the stimulus (from Dec 2008 to March 2009) the average exchange rate for the \$AU and the \$US was .67\$US = 1\$AU .
} 
In this paper we use observations of monthly EGM revenue to determine the extent to which the two stimulus packages influenced household expenditure on EGMs and increased the subsequent state tax revenues. We focus on three Australian states for which sufficiently detailed gaming expenditure data is made public. The rest of the paper proceeds as follows. Section 2 discusses the details of the economic stimulus packages. There is also a review of previous research that examines the impact of stimulus payments on consumer spending. Section 3 looks at the characteristics of EGM gambling. Monthly data from these states is used in Section 4 to estimate the impact of the stimulus payments on gaming expenditures. In Section 5 we estimate an income elasticity for EGMs based on our result. Since for most Australian states and territories, EGMs are by far the largest single source of gambling tax revenue, we estimate the extent to which tax revenue to the states was increased via EGMs in Section 6. Section 7 discusses evidence from other countries on the relationship between gambling and stimulus payments. Finally, Section 8 presents conclusions.

\section{Economic Stimulus Package}

Soon after the worldwide financial market downturn in October 2008, the Australian Federal Government announced two economic stimulus packages. In the first, entitled Economic Security Strategy, cash bonuses were paid to low income families and pensioners in December 2008. On average, payments to pensioners represented increases to their annual income of about a 6-7\% and to low-income families around a 5\%. In total there were 5.5 million separate payments to low income households totalling $\$ 8.7$ billion. The largest proportion of these payments occurred on the $11^{\text {th }}$ of December 2008 which coincided with the date for aged pension payments (Reserve Bank of Australia 2009).

A second stimulus package, (as part of the Nation Building and Jobs Plan) announced in Feb 2009 included a means tested cash bonus to Australian taxpayers. The payments totalled $\$ 7.3$ billion were made by the Australian Tax Office and began early April and consisted of 4.3 million stimulus cheques over a 5 week period and 3.7 million direct credit payments (Reserve Bank of Australia 2009). The package also included other household payments to eligible families with children totalling $\$ 5$ billion. These payments were paid electronically on the $11^{\text {th }}$ of March 2009 (Reserve Bank of Australia 2009). Households could receive multiple payments. Modelling of this package showed that only $18.5 \%$ of low income families gained from this package and the average payments were $\$ 1,508$ per family, which represented around a $7 \%$ increase in their annual income. Those in the middle income bracket gained an average of about $\$ 1,664$ per family or around a 5\% increase in their annual income and those in the high income bracket about $\$ 1,248$ per week or around a $2 \%$ increase their annual income. The group benefitting most were sole parent families and families with dependents as these groups were more likely to receive multiple payments (see Tanton 2009).

Previous research has suggested that small windfalls, around the size of 5\% or less of permanent income, appear to lead to greater spending and thus may help stimulate a recovery over recessions (Keeler et al. 1985). Australia was not alone in using stimulus packages to support household consumption and to reduce their exposure to the global financial crisis of 
2008-9. Recently, there have been a number of papers that examine the impact of these transfers on consumer spending in the US as well as in Australia.

Sahm, Shapiro and Slemrod (2009) estimate the effects on consumer spending of the $\$ 96$ billion in one-time stimulus payments US households received as part of the Economic Stimulus Act of 2008 that targeted low and middle income taxpayers. Eligible single individuals received between $\$ 300$ and $\$ 600$ and married couples received between $\$ 600$ and $\$ 1,200$. Those with dependent children received an additional $\$ 300$ per child. About 120 million individuals received a rebate which was distributed either electronically or via a paper check. Using survey data they conclude that approximately $20 \%$ of respondents reported that the stimulus payments led them to increase spending. Of those that spent their payments their response was quick. More than half of spenders cited that they spent the rebate on food and recreation. The older the respondent the more likely they were to spend the rebates. The low-income/low-wealth households spent their payments the most quickly.

Parker et al (2011) also analysed consumer spending resulting from the US payments and concluded that households spent an average of $12-30 \%$ of the stimulus payments on nondurable consumption goods during the 3 month period in which the payments were received. In addition, there was no significant difference between those households who received payments by check or electronic transfer.

Leigh (2009) examines the impact of the 2009 Australian stimulus payments. Also, using survey evidence he concludes that approximately $40 \%$ of households claimed to have spent the bonus payments. This corresponds to almost double the response of the US residents who received the 2008 tax rebate. One suggestion for this higher response in Australia is that the Australian stimulus payments were referred to as "bonuses" whereas the US stimulus payments were paid as "tax rebates" (Epley et al. 2006).

Although this research suggests that a greater percentage of households in Australia spent stimulus payments than in the US, the US research indicates that those households that did spend their payments spent them quickly and were likely to spend it on specific items such as food and recreation. In Australia, newspaper articles began to proliferate that attributed a surge in pokie spending to the economic stimulus packages. After the first stimulus package the manager of one Melbourne Tabaret hotel was quoted as: "I know what day the pensioners got their money: it was December 11 ... You occasionally get one or two waiting at the door (but that day)...it was a long, long line. We ended up calling it "Kevin Rudd Thursday" because all the old boys were saying how they were spending their handouts" (Reilly 2008). ${ }^{4}$

The use of ex post surveys to determine the expenditure of stimulus package payments on EGMs would be expected to be subject to similar difficulties encountered with other household expenditure surveys measuring gambling behaviour even where gambling is not illegal. The Australian Bureau of Statistics (ABS) notes that the reported level of gambling expenditures in the Australian Household Expenditure survey may be "well below

\footnotetext{
${ }^{4}$ Kevin Rudd was the Prime Minister of Australia at the time of the Economic Stimulus payments.
} 
the expected level" (ABS page 65 2007). An Australian Government Productivity

Commission report on projections of government revenue estimates conclude that such surveys could be off by a factor of 5. For example, they estimate from the 98/99 ABS Household Expenditure Survey that total gambling expenditure in Australia was $\$ 2.2$ billion while a total of the individual states gambling expenditures that is based on tax collection put the figure closer to $\$ 12$ billion. (Australian Productivity Commission section T10.2, 2005). In this study we will use a unique set of monthly revenue totals reported by three of the largest Australian states with EGMs.

\section{Electronic Gaming Machines in Australia}

In 1956, poker/slot machines (or pokies as they are referred to in Australia) first became legally available on a wide scale in the Australian state of New South Wales (NSW) when 952 venues were allowed to house a total of 5,588 machines. These machines were mainly located in registered sports and social clubs with the stated aim to generate income for improved facilities and amenities for the members. The popularity of these machines grew rapidly with the introduction of electronic versions of the old mechanical "one armed bandit" machines and the phasing out of machines that used only small denomination coins. By 1975 1,494 NSW gaming venues housed a total of 39,768 machines. ${ }^{5}$

Starting in 1992, EGMs have been progressively introduced in widely dispersed venues in all Australian states and territories except for the state of Western Australia (WA) where they are only available in a single Perth casino (Productivity Commission 2009). By 2009, EGMs accounted for approximately $65 \%$ of all Australian gambling expenditure. EGMs also serve as the main means of addiction for around $75-80 \%$ of problem gamblers (Delfabbro and Le Couteur, 2007). In 2007-08 Australians spent close to $\$ 10.1$ billion on EGMs in clubs and hotels and $\$ 1.3$ billion on those located in casinos. Outside of WA and the Northern Territory, EGMS located in hotels and clubs also comprise the single largest source of gambling tax revenue for every other Australian State and Territory.

\subsection{Characteristics of EGM gamblers}

As noted above, the Australian economic stimulus payments were primarily directed to low income persons and pensioner groups. Previous research has found a strong relationship between membership in a disadvantaged social group and gambling on EGMs. In addition, when EGMS are not restricted in location, a number of studies have found that they tend to be positioned in more socio-economically disadvantaged regions (Marshall and Baker 2001; Gilliland and Ross 2005). It has also been found that lower income households tend to spend disproportionately more of their income on gambling than higher income households (Marshall 2000). High levels of EGM spending appears to be over-represented by persons who are: recipients of social benefits, living in public housing, living in one

\footnotetext{
${ }^{5}$ These figures were obtained from annual New South Wales Treasury documents.
} 
bedroom accommodation and under 30 years of age (State Government of Victoria, 1994). Evidence from Sweden found that individuals supported by the social welfare system are more likely to experience gambling problems (Volberg et al. 2001). The Australian government's decision to distribute the predominant portion of the stimulus payments to these individuals might have inadvertently aided habitual gamblers.

Additionally, older gamblers have limited incomes and most of them spend only an amount they can afford. However, while seniors' gambling participation is lower than for the rest of the population, their EGM gambling usually takes place in licensed clubs where their participation tends to be higher than most other age groups (McCormack et al. 2003). The most common source of their gambling funds is discretionary income described as pocket money or from the household or personal entertainment budget (Roy Morgan 1997).

A recent survey conducted by the Victorian Department of Justice (2011) concluded that the stimulus payments did not appear to encourage people to shift their gambling habits. That is, there was no evidence to suggest that those individuals without gambling problems developed them after having received the stimulus payments.

\subsection{EGMS in South Australia; Queensland and Victoria}

Due to limitations on the availability of monthly gaming expenditure data across all Australian states, we examine three of the four major states that have widely distributed EGMs. EGM revenue data for South Australia, Queensland and Victoria is regularly available online. ${ }^{6}$

In South Australia and Queensland, clubs and hotels buy or lease their machines which are then monitored by Government approved agencies and the venues pay tax on its gaming revenue. However during this period in Victoria, only two corporations (Tatersalls and Tabcorp) were licensed to own and lease all the gaming machines in Victorian clubs and hotels. By law they were required to divide the machines equally between them. These three states introduced EGMs in the early 1990s. Subsequently, each state introduced similar measures to curb problem gambling. These measures included policies such as caps on the number of EGMs, smoking bans in gaming venues and restrictions on operations hours. However, there are major differences across the states particularly on the number of EGMs per capita and the gaming revenue generated from these machines.

\footnotetext{
${ }^{6}$ The sources of the data are www.vcgr.vic.gov.au; www.olgc.sa.gov.au; www.olgr.qld.gov.au. New South Wales is traditionally much less forthcoming about the provision of details of their gambling industry.
} 
Table 1. EGM Gaming per Person 2008-2009 financial year in the Australian states of Queensland, South Australia, Victoria and New South Wales.

\begin{tabular}{|c|c|c|c|c|c|c|}
\hline State & $\begin{array}{l}\text { Adults } \\
1,000 \mathrm{~s}^{\mathrm{a}}\end{array}$ & $\begin{array}{c}\text { Total Net } \\
\text { Exp }^{\mathrm{b}} \$ \text { Mill }\end{array}$ & $\begin{array}{l}\text { Num EGMs } \\
\text { (June 2009) }\end{array}$ & $\begin{array}{c}\text { Net \$Exp } \\
\text { /Adult }\end{array}$ & $\begin{array}{c}\text { EGMs/1000 } \\
\text { Adults }\end{array}$ & Net \$Exp /EGM \\
\hline Victoria & 4,228 & 2,707 & 26,772 & 640.34 & 6.33 & 101,000 \\
\hline Queensland & 3,353 & 1,861 & 41,775 & 554.90 & 12.46 & 45,000 \\
\hline South Australia & 1,270 & 751 & 12,737 & 591.06 & 10.03 & 59,000 \\
\hline $\begin{array}{l}\text { New South } \\
\text { Wales }\end{array}$ & 5,942 & 4,772 & 95,605 & 803.16 & 16.09 & 50,000 \\
\hline \multicolumn{7}{|c|}{$\begin{array}{l}\text { a The adult populations are defined as the number of persons in the state estimated to be } 18 \text { years of age or older by } \\
\text { Australian Bureau of Statistics Report } 3101.0 \text { Australian Demographic Statistics. }\end{array}$} \\
\hline
\end{tabular}

The data for the 2008-2009 financial year are summarized in Table 1 along with the available annual total for New South Wales for comparison. From this table we note that although both Queensland and South Australia have close to double the number of machines per capita than in Victoria, Victorians spend more per capita than either of these other two states and each machine in Victoria averages almost twice the revenue than any other state. We also note that while NSW has almost three times the number of machines per capita than Victoria, the Victorian machines generate more than double the income per machine.

The greater profit per machine (assuming homogeneous machine costs) in Victoria could be attributed to two main differences: the existence of a duopoly coupled with a restriction on the total number of machines. Marshall and Baker (2002) describe how the location of Victorian EGMs changed after their initial introduction in such a way as to increase the concentration of machines in lower socio-economic areas in order to maximize the revenue under the state mandated constraint on the total number of machines. New South Wales did not restrict the total number of machines and the distribution of the machines was less well coordinated in both South Australia and Queensland where EGM ownership was not dominated by a duopoly. 


\subsection{Monthly Observations for Three States.}
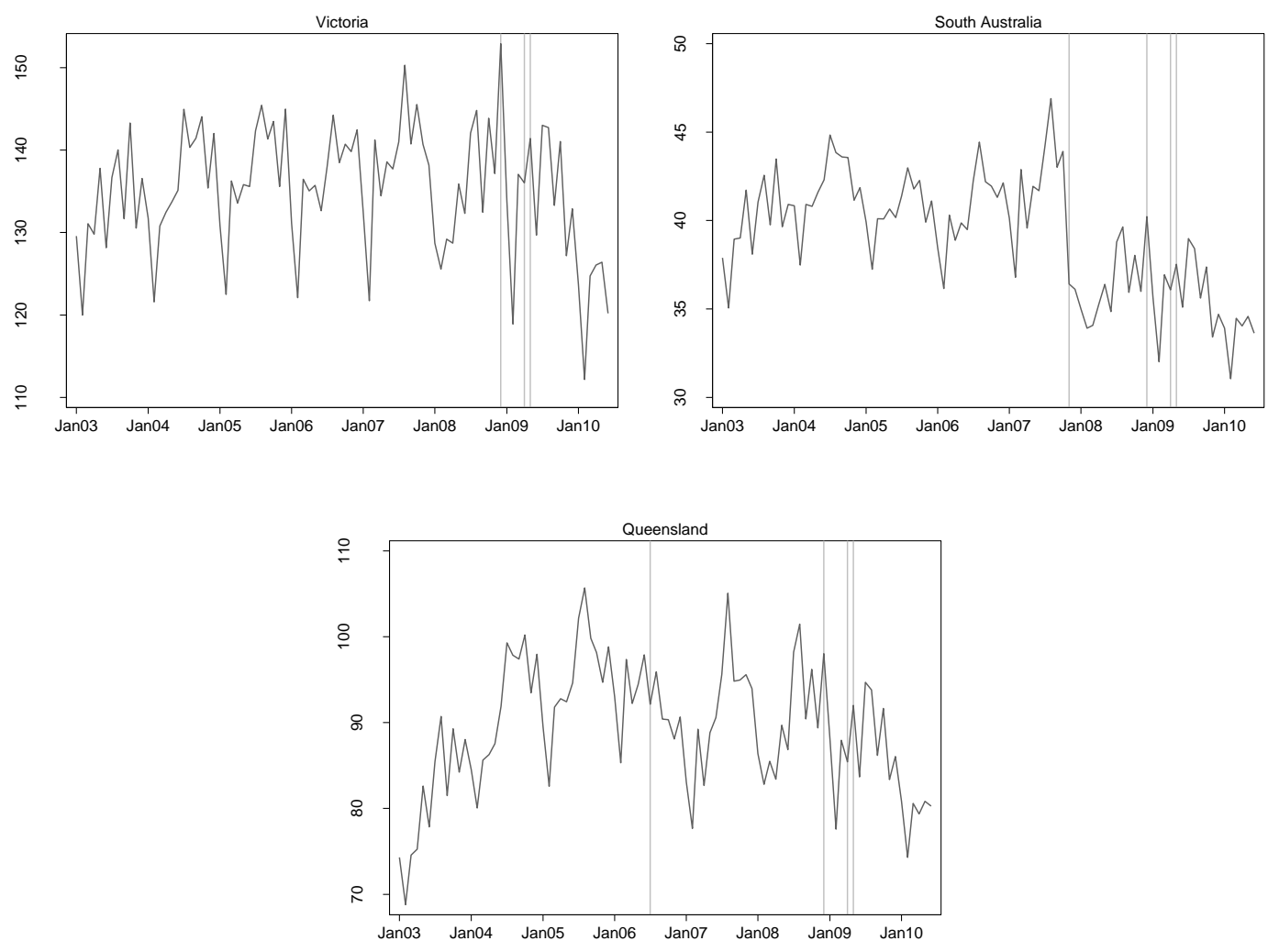

Figure 1 Total Real Net EGM Expenditure (in \$1989/1990)

Figure 1 is a plot of the monthly real total net expenditure for each of the three States we are able to observe in detail. The first reference line in the Queensland and South Australian plots correspond to the timing of the introduction of smoking bans in gaming rooms. Victoria instituted an equivalent smoking ban prior to 2002 and a further qualification of this ban in November of 2007 (see Hirschberg and Lye 2010 for evidence of the impact of the introduction of the smoking ban in Victoria). The reference line in late 2008 in all the plots corresponds to the timing of the payments associated with the first stimulus package. The two reference lines in early 2009 in all the plots correspond to the interval over which payments were made with the second stimulus package. 

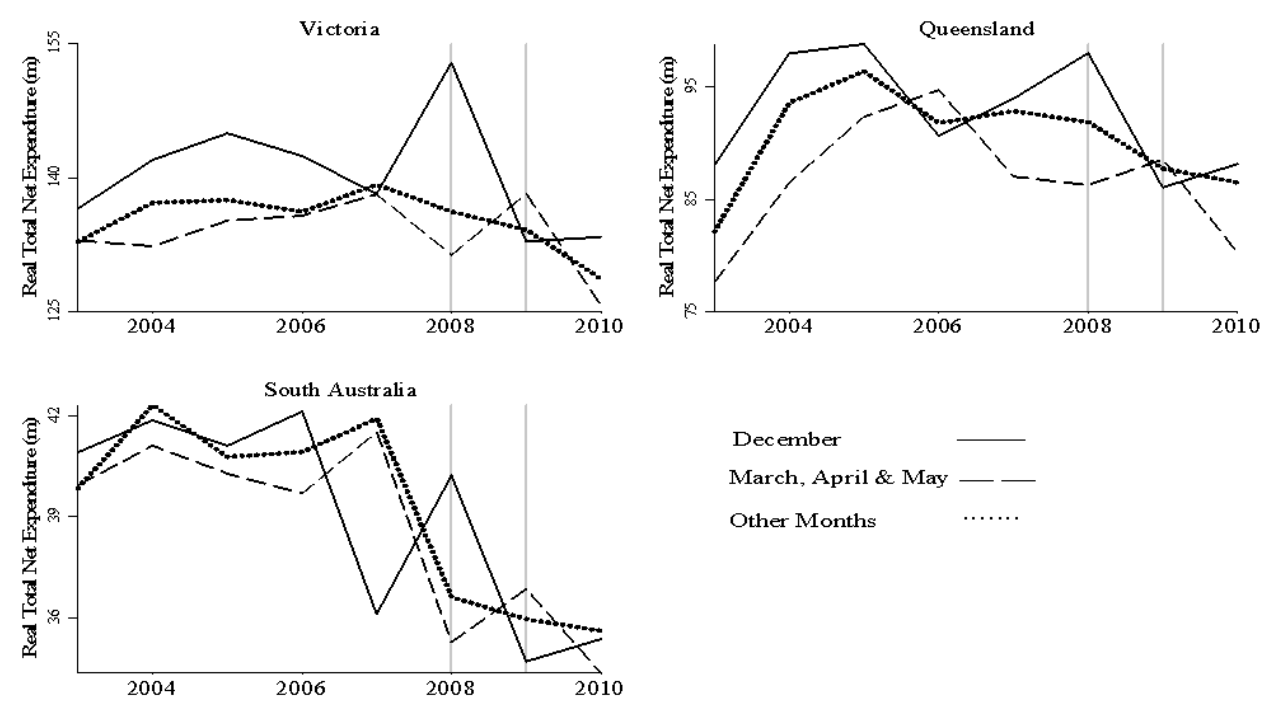

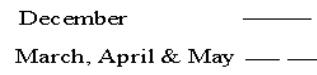

Other Months

Figure 2 The Annual average Total Real Net Expenditure (1989/1990=100) for December, March April and May, and all other months.

In Victoria, the real total net expenditure follows a regular seasonal pattern prior to the stimulus packages whereas the seasonal pattern for both Queensland and South Australia are affected by the introduction of a smoking ban. To graphically examine how real gaming expenditure is affected during periods of the stimulus packages we have removed the seasonal impact by plotting three sets of average annual values based on particular months in Figure 2. This figure displays the annual values for the following sets: December observations, the average for March, April and May observations, and the average for the remaining months' observations for the time period. For Victoria, there is a clear spike in December 2008, which corresponds to the first stimulus package. There is also a spike in the average on March, April and May the period corresponding to the second stimulus package. However, the average of other months continues to fall over these two periods. These spikes are also seen in the plots for Queensland and South Australia.

\section{Estimation}

To estimate the impact of the economic stimulus package on gaming expenditure, we use the monthly observations for net EGM expenditure and the number of EGMs for clubs and hotels located in Victoria, South Australia and Queensland over the period from January 2003 to June 2010 as discussed above in Section 3.3. We use an event study strategy by defining an equation for each state where the dependent variable is the log of total real net gaming expenditure (TNE in \$1989/1990) and regressors include the log of the number of EGMs (EGM), an indicator variable (Smoke) to account for changes in EGM demand that was influenced by smoking bans in gaming venues and a series of indicator variables that correspond to the periods of the stimulus payments. The variable $D_{12}$ corresponds to December 2008 and $D_{3}, D_{4}$ and $D_{5}$ correspond to the period of the second stimulus package, March, April and May 2009 respectively. To remove the monthly seasonal pattern in total 
net gaming expenditure a 12 period difference was applied (using the lag operator this is defined as $\left(1-L^{12}\right)$ such that: $\left.\left(1-L^{12}\right) x_{t}=x_{t}-x_{t-12}\right)$. The equation for each state is defined as:

$$
\begin{aligned}
\left(1-L^{12}\right) \log \left(T N E_{i t}\right)= & \beta_{1}\left(1-L^{12}\right) \log \left(E G M_{i t}\right)+\beta_{2}\left(1-L^{12}\right) \text { Smoke }_{i t} \\
& +\beta_{3}\left(1-L^{12}\right) D_{12 t}+\beta_{4}\left(1-L^{12}\right) D_{3 t} \\
& +\beta_{5}\left(1-L^{12}\right) D_{4 t}+\beta_{6}\left(1-L^{12}\right) D_{5 t}+\varepsilon_{i t} \quad ; i=1,2,3
\end{aligned}
$$

The three state equations are jointly estimated using Zellner's (1962) Seemingly Unrelated Regressions (SUR) model that includes an autoregressive error process that varies by state and was estimated using the package Eviews 7.0. These specifications were based on individual equation estimates using the Lagrange Multiplier test for autocorrelation and the Ljung-Box Q statistics. Inspection of the correlograms of the residuals from each equation in

\begin{tabular}{|c|c|c|c|c|c|c|}
\hline \multicolumn{7}{|c|}{ Dependent Variable: $\left(1-L^{12}\right) \log$ TNE 2003:1-2010:6 } \\
\hline & \multicolumn{2}{|c|}{ Victoria } & \multicolumn{2}{|c|}{ South Australia } & \multicolumn{2}{|c|}{ Queensland } \\
\hline Variables & Estimates & p-value & Estimates & p-value & Estimates & $p$-value \\
\hline $1-L^{12} \log E G M$ & -0.2099 & 0.738 & 0.1289 & 0.018 & 0.7553 & 0.100 \\
\hline $1-L^{12}$ Smoke & -0.0214 & 0.030 & -0.1426 & 0.000 & -0.1222 & 0.000 \\
\hline $1-L^{12} \quad D_{12}$ & 0.1045 & 0.000 & 0.1045 & 0.000 & 0.1045 & 0.000 \\
\hline $1-L^{12} \quad D_{3}$ & 0.0557 & 0.000 & 0.0557 & 0.000 & 0.0557 & 0.000 \\
\hline $1-L^{12} D_{4}$ & 0.0294 & 0.030 & 0.0294 & 0.030 & 0.0294 & 0.030 \\
\hline $1-L^{12} \quad D_{5}$ & 0.0742 & 0.000 & 0.0742 & 0.000 & 0.0742 & 0.000 \\
\hline \multicolumn{7}{|l|}{ Error term } \\
\hline$A R(1)$ & 0.3492 & 0.000 & & & 0.2452 & 0.007 \\
\hline$A R(2)$ & & & 0.1885 & 0.009 & 0.1091 & 0.201 \\
\hline$A R(3)$ & 0.3781 & 0.000 & 0.4351 & 0.000 & 0.5318 & 0.000 \\
\hline$A R(12)$ & -0.3543 & 0.000 & -0.2682 & 0.001 & -0.2103 & 0.001 \\
\hline$R^{2}$ & \multicolumn{4}{|c|}{0.6438} & \multicolumn{2}{|c|}{0.828} \\
\hline
\end{tabular}
the joint estimation indicated each was white noise.

Table 2. SUR Estimation Results by state using monthly observations from 2003:1-2010:6 where the stimulus response is assumed the same across states.

Although we originally estimated this model with different coefficients across the states for the event dummy variables corresponding to the stimulus packages, a subsequent Wald test indicated that we could not reject the hypothesis that these coefficients were equal in each State ( $p$-value 0.23). The SUR model was then re-estimated restricting these coefficients to be the same across the States. These results are presented in Table 2. All the coefficients for the dummy variables corresponding to the stimulus packages are significant. The first package is associated with a significant increase of $10 \%$. The second stimulus 
package is associated with a significant $16 \%$ increase (std error $=0.025)$. A Wald test rejects the hypothesis that the impact of the two stimulus packages was the same $(p$-value $=0.038){ }^{7}$

In summary, we found a significant increase in gaming expenditures of approximately $10.4 \%$ for the first stimulus and $15.9 \%$ for the second stimulus for a total of approximately $26.3 \%$ for the 4 months. A test of the hypothesis that the impact was the same across the states could not be rejected. However, a test of the hypothesis that the two stimulus packages had the same impact on EGM revenues could be rejected (at the $.05 \%$ level). Payments in the first stimulus were targeted at low income households and pensioners. The payments for the second were given to a wider group with a diverse range of income households benefitting. This provides corroborating evidence with numerous media reports at the time that there was a surge in pokie spending with economic stimulus payments (see eg. Reilly 2008; Dowling 2009). ${ }^{8}$

\section{A Short-run Income Elasticity}

Income elasticity is a measure of the percentage change in the quantity demanded for a particular good or service given a percentage change in income when prices remain constant. Using the results reported in Table 2 we can estimate the short-run aggregate disposable income elasticity for electronic gaming machines. By rescaling our total $26.3 \%$ increase for 4 months we obtain an approximate $20 \%$ increase for a three month quarter. The total of the two stimulus packages paid directly to households was $\$ 21$ billion and the average total gross disposable income was measured as $\$ 215.4$ billion in the last quarter of 2008 and $\$ 198.0$ billion in the first quarter of 2009 (in current dollars). ${ }^{9}$ Thus we can use an average of $\$ 206.7$ billion as the quarterly disposable income which implies that the stimulus increased quarterly income by approximately $10 \%$. Thus a $10 \%$ rise in the total quarterly income resulted in a $20 \%$ increase in gaming for an aggregate elasticity of 2 for the stimulus as it was paid. ${ }^{10}$ Alternatively, we can estimate that a marginal propensity to gamble on pokies is about .042 when 21 billion in stimulus increased EGM expenditures by $\$ 884$ million. $^{11}$

\footnotetext{
7 Note in this case we explicitly do not use HAC standard errors due to possible generation of inconsistent inferences as noted by Fomby and Murfin (2005) for similar event studies.

8 A further check of this specification was made where event dummy variables where included for all other December, April, May, and June combinations possible in the span of the data and no other combination was found to have any significant positive impact on demand.

${ }^{9}$ Source: Australian National Accounts publication ABS 5206.0 Table 14 Household income account, current prices.

${ }^{10}$ Note that this is not an estimate of individual income elasticity for gaming. Because most of the stimulus was paid to households that are on the lower end of the income distribution - the estimate for the disposable income of those individuals who received the payments is probably too high which would make their \% increase in quarterly income higher and thus lower the implied elasticity. Also because there was little price variation over this period we can assume the shift in demand was predominantly due to the short-run income shock.

11 Note that the Australian government's stimulus to the construction industry via infrastructure investment is not included in this amount since its influence on disposable income would have occurred over a much longer period.
} 
Since Suits (1979) estimated an income elasticity for horse racing of between .86 and 1.05 , a number of subsequent studies have estimated income elasticities for gambling. However, few of these explicitly examine electronic gaming and most are based on potentially biased household expenditure surveys instead of actual expenditures. In their 1999 study of the Australian gambling industry the Productivity Commission (PC 1999) assumed an income elasticity of .79 for all gambling. Recently Perez and Humphreys (2011) use micro data for expenditure on Spanish lotteries to estimate the income elasticity, conditional on the decision to gamble, is approximately 1.8 .

\section{Tax Revenue Impacts}

Traditionally, gambling policy in Australia is the responsibility of the States and Territories who have come to rely on them as a significant source of tax revenue. Table 3 shows the percentage of total State and Territory revenue that is derived from all forms of gambling and EGMs in particular. Furthermore, the taxation rates levied on gaming machines vary by location and type of venue. Since the tax receipts are determined by gaming expenditure, one would expect that the stimulus payment induced increase in gaming expenditure would flow to taxation revenues. One Australian legislator that has long been a critic of EGMs suggested this may occur when he stated that the stimulus "has simply gone from the Federal Government to the hip pocket of the pokie barons and the State Government" (see Vaughan 2009). In this section we estimate the degree to which the stimulus payments had an impact on taxation revenue collected in the three States being examined.

Table 3. All Forms of Gambling Taxation and EGM Taxation as a percentage of Total OwnState and Territory Tax Revenue 2008-09 ${ }^{12}$

\begin{tabular}{|l|r|r|}
\hline \multicolumn{1}{|c|}{ State/Territory } & All Gambling(\%) & EGM(\%) \\
\hline New South Wales & 9.2 & 5.9 \\
Victoria & 13.1 & 8.0 \\
Queensland & 10.4 & 6.6 \\
South Australia & 11.5 & 8.3 \\
Western Australia & 3.3 & NA \\
Tasmania & 11.7 & 7.3 \\
Northern Territory & 18.0 & 0.7 \\
Australian Capital Territory & 5.0 & 3.3 \\
\hline
\end{tabular}

To obtain a predicted value for total net expenditure for the financial year 2008-09 for the States of Victoria, Queensland and South Australia we adjusted the actual net expenditures for December 2008, March-May 2009 using the estimates obtained for the dummy variables corresponding to these months in Table 2 . Thus we assumed that the values for total net expenditure for the other months in the financial year 2008-09 are unchanged. This is consistent with models estimated that included dummy variables for every month but 
where it was found that only the months corresponding to the stimulus payments had significant coefficients. For the other States, we approximated the predicted total net expenditures assuming no stimulus payments using available annual data and the total increase in gaming expenditures as estimated in Section 3.

Tax rates on gaming are different across the States (see SACES 2006). However, given that this tax rate is related to gaming expenditure we estimate an effective gaming tax rate by taking the proportion of actual own-State tax revenue to total net expenditure. These effective tax rates are then used to calculate the predicted value of own-State tax revenue if stimulus payments had not been received. Actual own-State revenue and predicted own-State revenue without stimulus payments are shown in Table 4. A comparison of the difference between these values indicates that the State Governments did indeed receive more gaming revenue than it otherwise would have if there had not been stimulus payments. We predict that the own-State revenue in each State was approximately $2 \%$ higher due to the stimulus payments. ${ }^{13}$ Thus for all Australian States and Territories with widely distributed EGMs over $\$ 60$ million in additional EGM tax revenue was collected that was directly due to the stimulus payments.

Most State Governments allocate part of gambling revenue to social programs such problem gambling services and research into the impact of gambling on the community. Some also allocate this revenue to health services. So an indirect outcome of the stimulus package was for State Governments to obtain additional tax revenue that could be used for these purposes.

Table 4. Effect of Stimulus Payments on Own-State Revenue Financial year 2008-09 due to increases in EGM spending (in \$1,000,000)

\begin{tabular}{|c|c|c|c|c|c|}
\hline State $^{a}$ & $\begin{array}{c}\text { Effective Gaming } \\
\text { Tax Rate }\end{array}$ & $\begin{array}{l}\text { Gaming Machine } \\
\text { Tax Revenue }\end{array}$ & $\begin{array}{c}\text { Estimated Tax Revenue } \\
\text { without Stimulus }^{c}\end{array}$ & $\overline{D i f f}^{l}$ & $\begin{array}{c}\text { Total Gambling } \\
\text { Taxes }^{b}\end{array}$ \\
\hline ACT & 19.5 & 34.1 & 33.4 & 0.7 & 51.7 \\
\hline NT & 33.0 & 25.9 & 25.4 & 0.5 & 73.6 \\
\hline Tas & 26.9 & 33.3 & 32.6 & 0.7 & 93.7 \\
\hline SA & 39.0 & 292.0 & 285.9 & 6.0 & 407.0 \\
\hline QLD & 29.5 & 548.0 & 536.7 & 11.3 & 922.0 \\
\hline Vic & 37.0 & $1,011.6$ & 990.8 & 20.8 & $1,648.6$ \\
\hline NSW & 21.5 & $1,047.0$ & $1,025.5$ & 21.5 & $1,625.0$ \\
\hline Total & & $2,991.9$ & $2,930.3$ & 61.6 & $4,821.6$ \\
\hline
\end{tabular}

b. Gaming Expenditure Values obtained from www.vcgr.vic.gov.au; www.olgc.sa.gov.au; www.olgr.qld.gov.au; $w w w . o l g r . n S w . g o v . a u$, and total gambling taxes and gaming machine tax revenue data come from State Budget papers. For Act, NT and Tas data is obtained from Australian Gambling Statistics, 1983-84 to 2008-09, 27th Edition. The Tasmanian figure includes Keno.

c. Using estimated values from the dummy variables in Table 2 to adjust the Total Net Expenditure. This assumes the other months the total net expenditure didn't change. However, coefficients on these dummy variables were insignificant

d. Difference between actual State gaming revenue and predicted revenue.

13 These calculations only take into take into account the revenue from gaming collected by the States. The Australian Government also charges a goods and services tax on gambling expenditure and this is also returned to the States and Territories. The amount States received as a result of the goods and services tax is not included in these calculations. 
There is also evidence that other countries have experienced similar phenomena as a consequence of stimulus payments. In April 2009 families in Japan as part of their stimulus programme were given cash handouts. Over the following six months stocks for the popular amusement arcade Pachinko machines were the best performing equities in the market (Lewis 2010).

In China, banks issued a record of 9.6 trillion yuan (\$US 1.45 trillion) in new loans in 2009 with the aim of boosting the economy by sponsoring viable projects. It has been estimated that 20-33\% of these loans found their way to the stock market, real estate market and gaming tables in Macau (Liang 2010). Figure 3a is a plot of the year-on-year growth of gross gaming revenue and tax revenue generated from gaming in Macau. In the first six months of 2009 there was a contraction in both series due to the global financial crisis as well as the imposition of tighter visa restrictions on Chinese visitors to Macau (see eg. Zhang and Kwan 2010). However, from the second half on 2009 substantial increases in both series can be seen.

Figure $3 \mathrm{~b}$ plots the year-on-year growth for three game types. While in the second half of 2009 there was an increase in growth for each game type, substantial increases can be seen in the VIP baccarat series. These are the VIP customers or the high-rollers whose bets represent about 80 percent of Macau's gaming revenues. It was predicted in the media that the flood of new liquidity would impact in particular on their habits (Lewis 2009). In the US, there were predictions that the Economic Stimulus \$US 100 billion rebates to taxpayers could generate an additional 1.3\% in the casino industry's expected revenue growth (Stutz 2008).
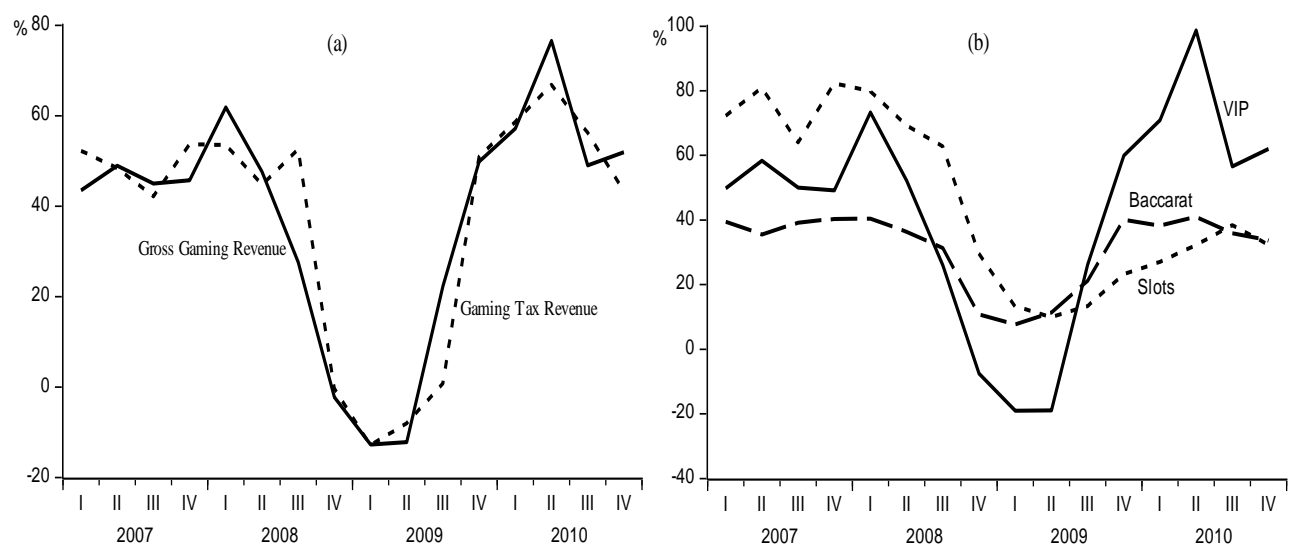

Figure 3 Year-on-year growth of Gross Gaming Revenue and Tax Revenue generated from gaming in Macau. ${ }^{14}$

\section{Conclusions}

In late 2008 and early 2009 the Australian Government instituted a number of economic stimulus packages to forestall the possibility of an Australian recession to be

\footnotetext{
${ }^{14}$ Data obtained for Figure 3a from www.dsec.gov.mo and for Figure 3b from www.dicj.gov.mo
} 
caused by the Global Financial Crisis. The intention of the household component of these packages was to boost consumption. However, headlines such as "Pokies binge follows hand-out" (Dowling et al. 2009) soon began to appear in the media which suggested that the stimulus payments may induce an increase in gambling.

Electronic Gaming Machines are widespread throughout Australia and account for $65 \%$ of overall gambling expenditure. However, they have also been associated with 75 to $80 \%$ of gambling-related problems. In addition, they constitute a significant source of tax revenue for most Australian States and Territories.

Using a unique set of monthly data from three Australian States we find that the stimulus packages resulted in a significant increase to gaming expenditures. The first package, mainly targeted at low-income households and pensioners, led to a $10 \%$ increase. The second that was targeted at a wider group of households, led to a $16 \%$ increase. We estimate that the short-run aggregate income elasticity of the stimulus package to be spent on EGMs was approximately 2. Primarily this was due to the direction of payments to households with a greater propensity to frequent the pokies and the wide-spread impression that this was extra income. In addition, we estimate that the increases in gaming expenditure have a flow-on effect to the gaming tax revenue collected by State Governments and Territories. For the States and Territories with widely distributed EGMs, we predict that the annual own-State gaming revenue for the 2008-2009 financial year was close to $2 \%$ higher due to the stimulus payments and this was estimated as over $\$ 60$ million in additional tax revenue.

Another aspect of stimulus packages is their indirect impacts as measured by the degree to which they generate income in other sectors of the economy via the multiplier. However, EGMs are the least labour intensive form of gambling. EGM venues are highly capital intensive and have few linkages to the local economy (Delfrabbro and Le Couteur 2003). One intended design feature of the EGM gaming experience is the minimisation of labour input and contact with others. Job intensity associated with EGM gambling in Australia is estimated to be about 3.2 jobs per $\$ 1$ million of gambling whereas the retail sector employs 6.5 persons per $\$ 1$ million of income (Saces 2006). Thus the degree to which stimulus payments are channelled to EGM steers the indirect impact away from those sectors of the economy with higher multipliers and job intensities.

Stimulus payments can also be expected to have impacts on other areas of gaming. Previous research has shown that lower income and older individuals are most likely to play the lottery compared to other demographic groups. Coughlin and Garrett (2009) show that marginal spending on lottery tickets of transfer income is larger than marginal spending on lottery tickets from either earning or wealth income. Although we do not have access to the equivalent detailed data on lottery sales, a comparison of the fiscal year 2008/9 State revenue derived from lottery sales was higher than the revenue forecasted in a number of State budgets. In Western Australia, where EGMs are only located in the casino, State revenue from lottery sales was $17.5 \%$ higher than forecasted. For the same fiscal year, in States 
where EGMs are prevalent, the increase in State revenue over that forecasted ranged from $1 \%$ in Queensland to $12 \%$ in South Australia.

The aim of the Global financial crisis fiscal stimulus package was to stimulate consumer spending with one-off cash bonuses. While these types of payments allow freedom of choice in spending they can be used to purchase services such as gambling. There are alternatives to cash bonuses. For example, an income management scheme designed to limit the range of goods and services that can be purchased with social security payments has been introduced in Australia's Northern Territory. Lamb and Young (2011) report that this scheme appears to have reduced the cash spent on EGMs. This would imply that future stimulus packages could be designed to minimise direct expenditure on EGMs. 


\section{References}

Australian Bureau of Statistics (ABS) (2007), Government Benefits, Taxes and Household Income, 2003-2004, \#6537.0.

Australian Productivity Commission, (1999), Australia's Gambling Industries: Inquiry Report. Volume 3 Appendices, November.

Australian Productivity Commission, (2005), Economic Implications of an Ageing Australia, Technical Report T10, Gambling Revenue.

Coughlin, C. and T. Garrett (2009), "Income and Lottery Sales: Transfers Trump Income from Work and Wealth", Public Finance Review, 37, 447-469.

Delfabbro, P. H. and A. Le Couteur (2007), A Decade of Gambling Research in Australia and New Zealand: Implications for Policy, Research and Harm Minimization. Report prepared for the Independent Gambling Authority of South Australia. http://www.iga.sa.gov.au/.

Dowling, J., M. Moncrief and P. Martin (2009), "Pokies binge follows hand-out; Figures indicate 'bandits' took plenty", The Age, January 24, Melbourne, Australia.

Epley, N., D. Mak and L. Idson (2006), "Bonus or Rebate?: The Impact of Income Framing on Spending and saving", Journal of Behavioral Decision Making, 19, 213-227.

Fomby, T and J. Murfin (2005), "Inconsistency of HAC standard errors in event studies with iid errors", Applied Financial Economics Letters, 1, 239-242.

Ife, H. and K. Collier (2008), "Shoppers urged to spend for Australia", Herald Sun, December 6, Melbourne, Australia.

Gilliland J. and N. Ross (2005), "Opportunities for Video Lottery Terminal Gambling in Montreal: An Environmental Analysis", Canadian Journal of Public Health, 96, 5559.

Keeler, J., W. James and M. Abdel-Ghany (1985), "The relative size of windfall income and the Permanent Income Hypothesis", Journal of Business and Economic Statistics, 3, 209-215.

Lamb, D. and M. Young (2011), "'Pushing buttons': an evaluation of the effect of Aboriginal income management on commercial gambling expenditure", Australian Journal of Social Issues, 46, 119-140.

Leigh, A. (2009), "How much did the 2009 Fiscal Stimulus boost spending? Evidence from a household survey", Centre for Applied Macroeconomics Analysis Working Paper No. 22/2209 September.

Lewis, L. (2009), "Chinese bail-out cash heads for Macau's casinos rather than Guagdong factories", The Times (London) Business, June 20, 51. 
Lewis, L. (2010), “Gambling dens eye up Japan's child subsidy; State pay-out is hidden bonus for pinball parlours", The Times (London) Business, March 11, 65.

Liang, Y. (2010), "China and the Global Financial Crisis: Assessing the Impacts and Policy Responses", China \& World Economy, 18, 56-72.

Hirschberg, J. G. and J. N. Lye (2010),'The Indirect Impacts of Smoking Bans in Gaming Venues", Current Issues in Health Economics, ed. D. Slottje and R. Tchernis, Contributions to Economic Analysis Vol 290, Emerald Publishing Limited, UK, pp 243-256.

Marshall, D. and R. Baker (2001), "Clubs, spades, diamonds and disadvantage: the geography of electronic gaming machines in Melbourne", Australian Geographical Studies, 39, 17-33.

Marshall, D. and R. Baker (2002), "The Evolving Market Structures of Gambling: Case Studies Modelling the Socioeconomic Assignment of Gaming Machines in Melbourne and Sydney Australia”, Journal of Gambling Studies, 18, 273-291.

Marshall, K. (2000) "Update on Gambling”. Perspectives on Labour and Income, 12, 29-35.

Marshall, K. and H. Wynne (2004), "Against the odds: a profile of at-risk and problem gamblers", Canadian Social Trends, 73, 25-29.

McCormack, J., Jackson, A. and S. Thomas (2003), "Gambling and older people in Australia”, Australasian Journal on Ageing, 22, 120-126.

Parker, J. A., N. Souleles, D. Johnson and R. McClelland (2011), "Consumer Spending and the Economic Stimulus Payments of 2008" NBER Working Paper No. 16684 January.

Perez, L. and B. R. Humphreys, (2011), “The Income Elasticity of Lottery: New Evidence from Micro Data", Public Finance Review, 39, 551-570.

Productivity Commission (2009), Gambling Draft Report, October, Commonwealth of Australia.

Reilly, T. (2008), "Rudd's handouts feed statewide betting binge”, The Age, 28 December, Melbourne, Australia.

Reserve Bank of Australia (2009), "The RBA's role in processing the Fiscal Stimulus payments" Reserve Bank of Australia Bulletin August Article 1.

Roy Morgan Research 1997, Older People and Gambling, report prepared for the Victorian Casino and Gambling Authority, September.

Saces (South Australian Centre for Economic Studies 2006), The South Australian Gambling Industry Final Report, Commissioned for South Australian Independent Gambling Authority http://www.iga.sa.gov.au/. 
Sahm, C., M. Shapiro and J. Slemrod (2009), "Household Response to the 2008 Tax rebate: Survey Evidence and aggregate Implications", NBER Working Paper Series 15421 October.

South Australian Centre for Economic studies (SACES, 2006), The South Australian Gambling Industry Final Report 2006, downloaded 23/3/2011 from www.iga.gov.au.

State Government of Victoria (1994). Review of electronic gaming machines in Victoria. Melbourne: State Government of Victoria.

Stutz H. (2008), "Inside Gaming: Stimulus payments may go out of pockets onto felt", Las Vegas Review-Journal, Business 1E.

Suits, D. B., (1979), "The Elasticity of Demand for Gambling”, The Quarterly Journal of Economics, 93, 155-162.

Tanton, R. (2009), Who received most from the household stimulus package?, Commentary at Australian Policy Online, http://apo.org.au/commentary/ who-received-mosthousehold-stimulus-package

Vaughan, J. (2009), "Xenophon says handout money was poured into pokies”, The Advertiser, January 18, Adelaide, Australia.

Victorian Department of Justice (2011), "The Victorian Gambling Study a longitudinal study of gambling and public health- Wave Two Findings", Department of Justice, State of Victoria.

Volberg R., M. Abbott, S. Rönnberg and I. Munck (2001), "Prevalence and risks of pathological gambling in Sweden”, Acta Psychiatrica Scandinavica, 104, 250- 256.

Zellner, A. (1962), “An Efficient Method of Estimating Seemingly Unrelated Regressions and Tests of Aggregation Bias", Journal of the American Statistical Association, 57, 500-509.

Zhang, Y. and F. Kwan (2010), "Financial Crisis offers Respite for the Macao Economy", in China and the Global Crisis, Series on Contemporary China Vol 22, eds Z. Yongnian and S. Tong, pp.159-178, World Scientific Publishing Co. Pte. Ltd. 


\section{University Library}

\section{- M M N E R VA A gateway to Melbourne's research publications}

Minerva Access is the Institutional Repository of The University of Melbourne

Author/s:

Lye, J;Hirschberg, J

Title:

Gambling with Stimulus Payments: Feeding Gaming Machines with Federal Dollars

Date:

2014-09-01

Citation:

Lye, J. \& Hirschberg, J. (2014). Gambling with Stimulus Payments: Feeding Gaming Machines with Federal Dollars. JOURNAL OF GAMBLING STUDIES, 30 (3), pp.713-727. https://doi.org/10.1007/s10899-013-9377-6.

Persistent Link:

http://hdl.handle.net/11343/283027 